\title{
INsideVisible Cities: Transcending Substance
}

\begin{abstract}
The interior, as one of the most human and sensual forms of architecture, is an intimate connection with the built environment and a powerful tool in provoking and altering the human mind, stimulating its curiosity, desires and solutions by way of visible and ambient matter. I aspire to explore the sense of interiority as betweenness, a space of transition in which both the human and the architecture body transcend from one state to another through empathetic interaction. Empathy, besides the ability to feel and experience someone else's emotions and mental state, also depicts our capacity to feel and experience situations, surroundings and non-living bodies. Interiority encounters three states of empathy in which our capacities of memory, imagination and illusion convey the invisible relationships we have with spaces and inanimate matter. Memory conveys the ability of both humans and space to encapsulate presence, activity and emotion through time. Imagination is our capacity to dream and inject a space with our own vision, shape and create new worlds. Illusion, on the other hand, forms a vigorous relationship with the human being through projecting its character and influence onto our minds. The interiority I seek to illustrate surpasses the rationalities, containment and materiality it is commonly related and rather stimulates curiosity in our being, revealing the qualities of a space as a living organism - growing, living, talking, affecting, absorbing, aging and eventually dying...
\end{abstract}

Keywords: empathy, memory, imagination, illusion, invisible 


\section{Introduction}

Spaces are powerful tools in provoking and altering the human mind, stimulating its curiosity, desires and solutions by way of visible and ambient matter. The interior, as one of the most sincere and sensual forms of architecture, is our most intimate connection with the built environment. In its essence, the interior, on which we are dependent physically and emotionally, should continuously enrich our everyday lives as well as the bond between one another, raising our awareness of space, time and matter in which we all coexist. In a world of rapid change, architecture among many other aspects of our modern culture has changed extensively and many of its priorities, devoted to enhancing the way people live, are challenged. Overwhelming materialism and digital stimulation in our cities have deprived us of the ability to understand our surroundings through sensual stimulation and feeling architecture in its totality - through the invisible. In order to remedy these forms of alienation, we need to look deeper into what defines us human, what sort of lives we want to live and what sort of spaces would protect and enrich those lives.

In phenomenological terms, our consciousness and deep understanding of being can be nurtured through architecture, which is not dependent solely on rationalization, function and visual dominance but rather is stimulating the senses and allowing the subjective and idiosyncratic experience of space. These experiences allow us to open up to external stimuli and become an active participant in the complex, symbiotic relationship between living and non-living matter.

Empathy is a term commonly used to describe the ability to feel and experience someone else's emotions and mental state. Although less familiar, empathy also depicts our capacity to feel and experience objects and inanimate matter, project ourselves on them and also inject their character back into us. By re-evaluating the environments and objects we are surrounded by, we can start perceiving them as almost living organisms, carrying memories, communicating stories, being affected by us and leaving impressions on us. Is it possible that through empathy with the spaces we live, we become more aware of our environment, more understanding of each other and of our own selves?

In this paper, I will explore how different ways of establishing empathetic relationships with spaces nurture our constant occupation of the built environment and stimulate our own desires for participation and creativity within it. By referring to contemporary spatial art and architecture literature as well as my 
personal projects and encounters, I would like to illustrate how the concept of interiority transcends the common notion of being a site of containment in favour of an interior as a space of transition in which both the human and the architecture body transcend from one state to another through mutual interaction.

Undergoing three phases of empathy, I aim to unpack the invisible relationships we have with spaces and inanimate matter in order to emphasize the importance of interiority in enhancing our understandings and feeling of our surroundings, of one another and also of oneself. In the first phase, mutual memory opens up the ability of both humans and space to encapsulate presence, activity and emotion through time passing it on to one another. Empathy through imagination is the second state and will reveal how each one of us sees our environment differently and our capacity to imagine and create projects onto the environment. And finally, I would like to reveal how illusion challenges our notions and is a powerful tool that the interior can use to project its character and influence our minds. The interiority I seek to illustrate surpasses the rationalities, containment and materiality it is commonly related to and rather stimulates curiosity in our being, revealing the qualities of a space as a living organism - growing, living, talking, affecting, absorbing, ageing and eventually dying...
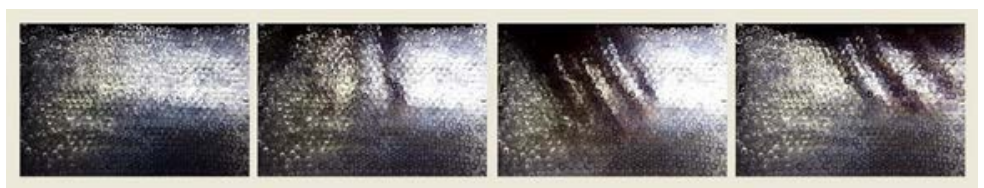

Figure 1

Vertical Village:

Author's project

\section{The Memory Palace: Transitions in Time}

Both the interior and the human are subjects of the processes of ageing and metamorphosis and their ephemeral and fragile qualities enhance and visualise the constantly evolving nature of their beings. Memory imprinted on the shells of human and architecture bodies allows understanding and penetration of their inner, hidden selves. In this first state, the building and the human simultaneously share emotions through past associations and reflect each other's ability to encapsulate presence, activity and emotion through time.

In a world of nomadic individualism, belonging to a place, a feeling deeply rooted in previous generations, is gradually fading away. Bringing our most valuable belongings and memory stimulating objects with us on every new terrain, we aspire to create a relationship with the new space that is less uncanny and more reminiscing of our past. Memories are what we consist of and 
interiors carry the traces of our encounters and actions to remind us of who we are, where we are from and who we have been with. The term memory palaces derives from ancient Rome where it was used to describe constellations of reminders attached to specific places and frequently utilized to make fast associations during speeches. The interior is indeed a memory palace, a space which one can relate to or as Hollis (2013 portrays it "a museum of the soul, an archive of its experiences" (p. 6). People identify themselves with the spaces they have inhabited and the inability to do so may result in losing one's sense of self. The mind carries its collection of associations, and through the body and its stimuli, it adds or modifies them continuously, reflecting the environment, objects and other beings it comes across. Forming a positive or negative emotional union with spaces and external objects fosters a subjective experience of our surroundings. By modifying our interiors and leaving our mark while living in them, they also modify and transform us, our memories and our attachments.

Gabriel Marcel claims "I am my body," Wallace Stevens argues "I am what is around me" and finally Ludwig Wittgenstein intensifies "I am my world" (in Pallasmaa, 2009, p.13) Indeed as we live in time and time lives in us, we also dwell in spaces and they, in return dwell in us. Similarly to the action of time on the human body, the action of time on the architecture body results in processes of ageing through erosion and decomposition. Time, however, adds more to the body than it takes away. It enhances the content and reflects its very existence through evidence of contact with other bodies marked on its skin and soul. The feeling of human nature's presence in space provokes a warm sense of nostalgia, through worn out and wrought features, which modern and shiny spaces lack...

It was the summer of 2000 when I first entered the beautiful valley of the Rhodopi Village Mugla and stayed overnight in the local school, which had been partially adopted as a guest house and could even be seen as a holiday retreat. Thirteen years later I visited the same village again with friends. Ruins, remains of old furniture, abandoned houses, looking like they are taking their last breaths before another slab decays and leads the whole structure into total decomposition. This was the scene that welcomed us into what was once the living village - forgotten overwhelmed by the forces of nature, nevertheless no less sincere and warm as it once was.

The two encounters with the same place intensified my vision in seeing the life of a building from its most active existence to its most quiet stage of becoming again one with nature. This scenery portrays how not just interiors appear and disappear all the time. Here, this temporality is expressed through the building, the 
whole architecture of a village, its streets, its people - gradually disappearing but leaving the palaces of their presence behind. Even though I did not see it as a school, when I first entered the building to stay overnight with my family, I could feel the once loud corridors, filled with reflections and refractions of sounds from children's footsteps and laughter. The walls were covered with drawings of students and the shelves were still full of books and toys, serving once as primary guides and first understandings of the world to the young students. More than a decade later, completely abandoned, I experienced the building as a stratum of numerous phases it had been through and the variety of guests it had welcomed. Enveloped in sinister beauty, the school seemed like it still had a life of its own, no longer interacting with human beings but solely with nature and its forces that gently subtracted from its physical presence, but nevertheless adding more value to its spiritual being.

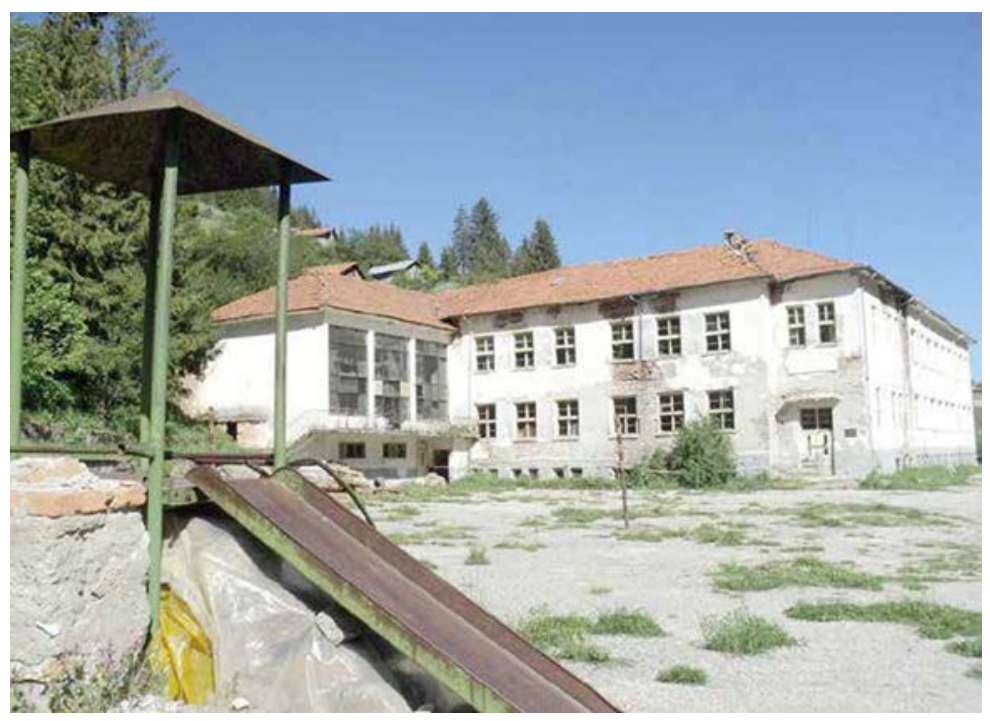

Figure 2

Mugla School Exterior

"Interiors are lost all the time - the way interiors are lost tells us as much more about them as the ways in which they were created or inhabited" (Hollis, 2013, p.10). In a way, being inside a building is being inside a body, experiencing its soul. My soul is dispersed around in many different places and interiors I have occupied in the last 10 years. Although none of them truly became a place I call home, I had left a piece of me in them and they had left their mark on me in return. Spread everywhere in my urge to discover more and more in this world, I have been leaving friends, family and belongings behind but always keeping them with me through my memory palaces. To portray through the words of Paterson: "a man in himself is a city, beginning, seeking, achieving, and concluding 
his life in ways, which the various aspects of a city may embody" (in Holl, Pallasmaa, \& Gomez, 2006, p. 13).

The need to share emotions, experiences and to record the presence of our being has been a human trait since our very evolving as human beings with cave paintings emerging more than 30,000 years ago. Today our memories are subjects of recording devices and our minds become more and more dependent on them. If we lose data, pictures or our social media accounts for even a short time, we feel anxious and empty because our memory palaces are deserted. The technology utilises the way we store information, however, it also takes away our experience of it and the curiosity of discovering and identifying characters of those who imprinted traces and hidden messages in our surroundings. Steven Holl believes that natural materials preserve the plasticity of a building and preserve our experience of space (Holl et al., 2006, p. 31). Undeniably, natural textures, colours, patterns and smells convey the true essence of materiality and respond to the natural course of life - reproducing, ageing, breathing, dying. The tendency to build in artificial and plastic materials to compete for the continuum of time with longevity deprives interior spaces of character and opposes their genuine nature of being provisional.

Figure 3 Layers of skin: House in Kyoto, Japan

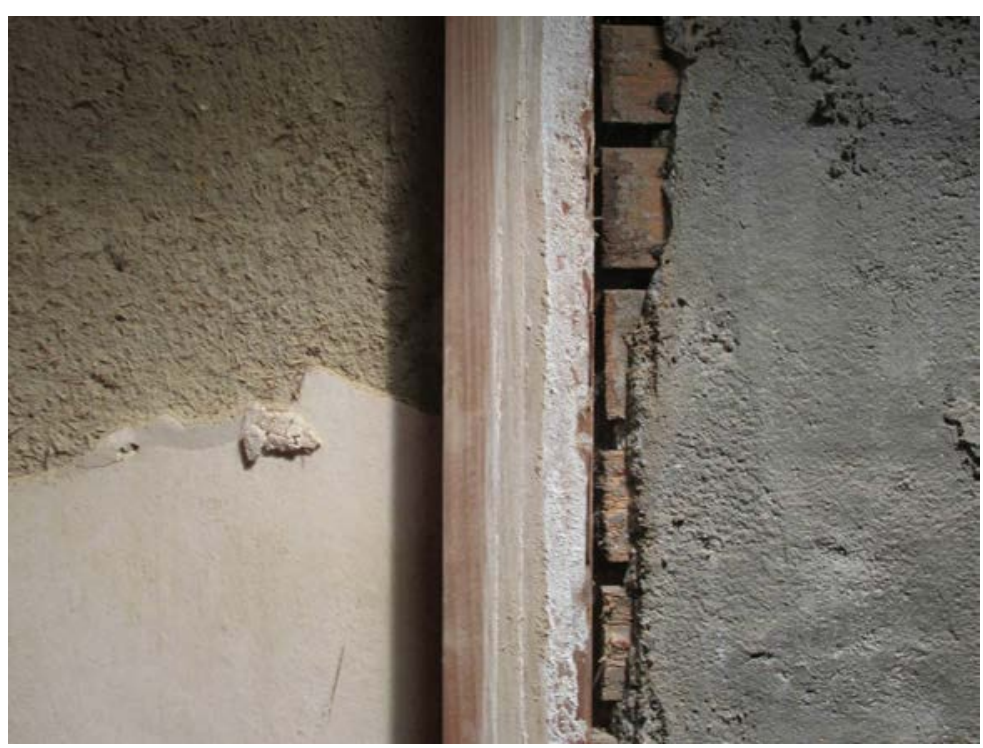

My fascination with abandoned places is one that admires nature's prevailing force, gracefully invading and beautifully decorating the spaces that no longer host human presence. As if it dreams to substitute them. The interior builds upon layers of history, and each alteration is a re-telling of a story of the building and its 
occupants as it existed in a particular time period. The interior is a constantly changing response to people's needs and lives that justifies the building's presence. Interiors exist in the continuum of time, undertaking different states of transition, to become collages, meeting points of architecture and design, of people and objects, of past and present and of living and dead. Careful attention has to be put in preserving the memory of old buildings when they need to be adapted to new functions. Re-adaptation should substitute renovation, and the designer's task is to inject new life into the old structure by enchanting its value and memories throughout the space, adding the next layer of its history instead of substituting it or locking it in a frame or behind glass.

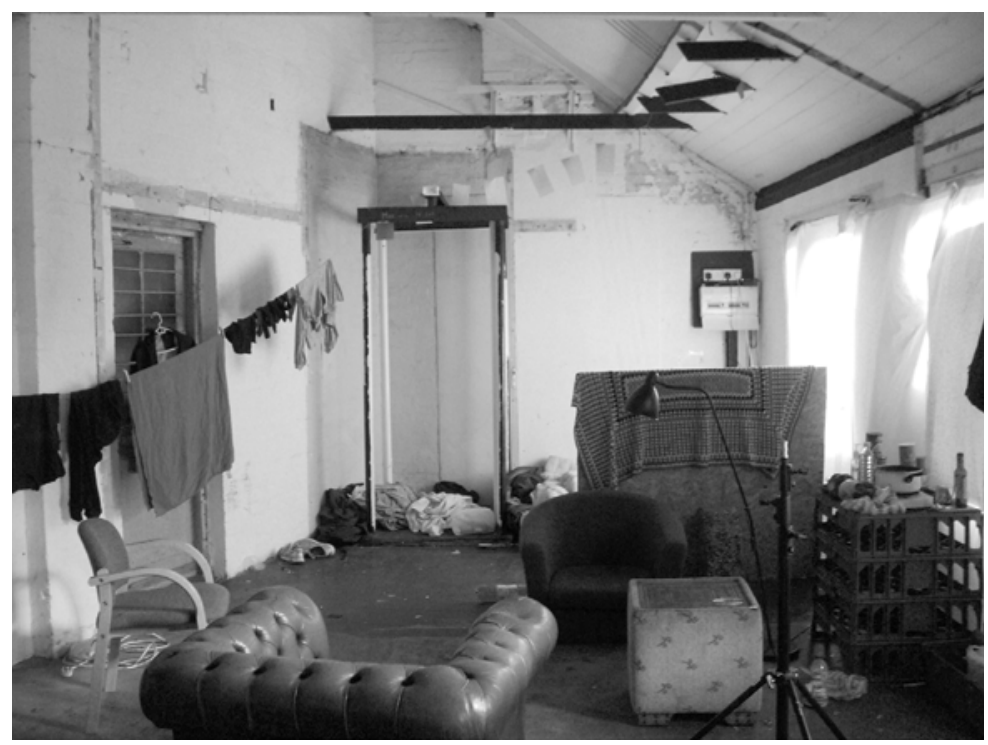

Figure 4

Re-adaptation: Squat house in London

Empathy through memory creates a simultaneous union between the space and the human, where they both can identify with each other's character, leave a mark on one another and eventually become part of one another. Interiors should guide us through the threshold of being and reveal the connection to our cultural and biological past. A person is a collection of spaces and memory palaces, what he or she will become depends on the imagination and even more so on the illusion.

\section{The Matter of Imagination: Transitions in the Void}

Gradually passing into the abstract and immaterial world, our capacity of imagination gives us the ability to dream and inject a space with our own characteristics, which plays a vital role in 
shaping our environment. This state goes beyond the senses and the physically present matter to rearrange the world as we know it and to project a piece of ourselves onto it. With the premise that architecture and design are the substantial matter that makes us question and wonder about our reality, the metaphysical should become an indispensable part of the spatial experience. Perceiving what is not physically there can take the form of imagination, when the human mind projects its thoughts onto the architectural body or illusion, when space itself has the power to change the awareness and perception of the human mind. Imagination is a non-separable part of the concept of empathy and renders vividly the ability of the mind to visualise and experience the sublime and extraordinary in the everyday and ordinary.

In his dream world novel, Invisible Cities, Calvino (1974) implies that at any given moment, there is more than one reality which we can experience through imagination. If we look at the world as more similar to the realm of dreams than to a scientific doctrine, we might experience existential and lived space rather than physical and geometric. The question of what a substance is was raised as early as $340 \mathrm{BC}$ by the Greek philosopher Aristotle, who claimed there is a unique single substance that interconnects all activity, matter and motion (as cited in Cohen, 2000). Similarly, the Japanese concept of $M a$, best described as "gap" or also as "the complex network of relationships between people and objects" (McLuhan, 2005, p. 157) is not created by compositional elements but takes place in the imagination of the viewer. This concept is superbly illustrated in Japanese architecture, where beauty and serenity rely solely upon the varieties of light and shadow, hitting still surfaces.

Figure 5 House in Kyoto, Japan

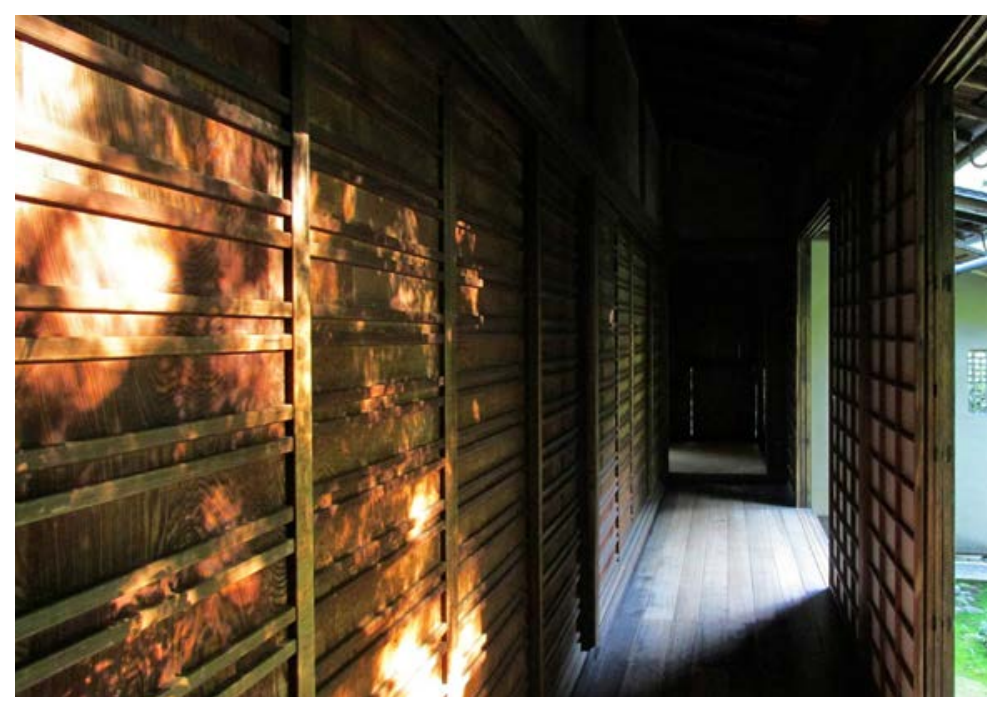


Many artists and designers have been attempting to visualise the immaterial negative space, $M a$, in order to find the mysteries behind the invisible. Henry Moore is one of the most prominent sculptors to be able to animate emptiness with life. He allows empty space to form an essential partnership with the solid, thus exaggerating the union between positive and negative, solid and invisible, where the void is the osculant union (Figure 6). In a more literal way, Rachel Whiteread's casts voids and negative space to portray what we do not see - the ghosts that surround us daily with a texture and a soul of their own (Figure 7).

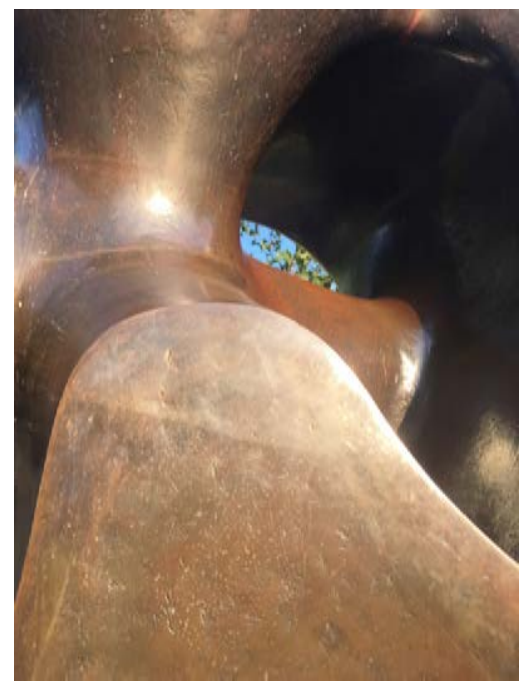

Figure 6

Large Spindle Piece by Henry

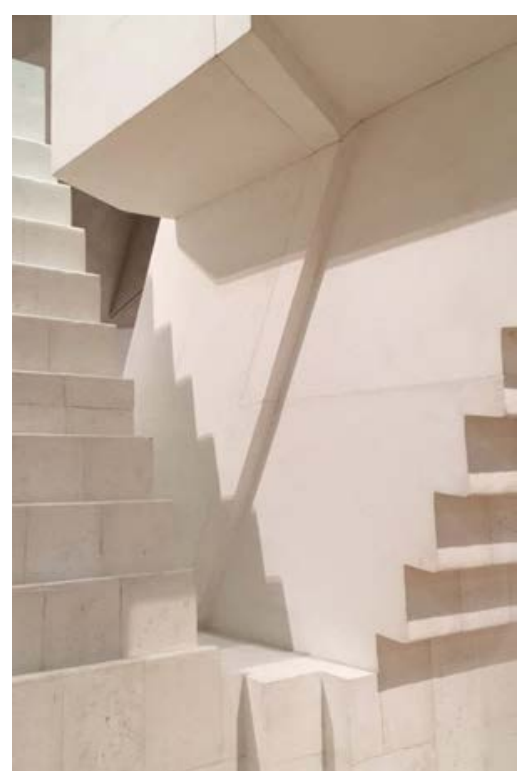

Moore

Figure 7

Sculpture by

Rachel Whiteread 
In a different manner, Christopher Bauder creates immersive installations through another intangible medium - light. His works use mirrors, projectors and sound to create multi-sensorial symphonies that embrace the visitors in unusual settings. When I visited his installation Skalar in Berlin (Figure 8), I noticed how people were completely submerged into the creation and every mind was reflecting and having a different experience in the same space. Indeed, I believe it is our capacity to create our own versions of where we are, be able to tell our own stories from the same places that is one of the greatest gifts we have as human beings. Interiors can stimulate our minds to create our own worlds and scenarios by leaving space, $M a$, for them to emerge.

Figure 8

Skalar by

Christopher

Bauder

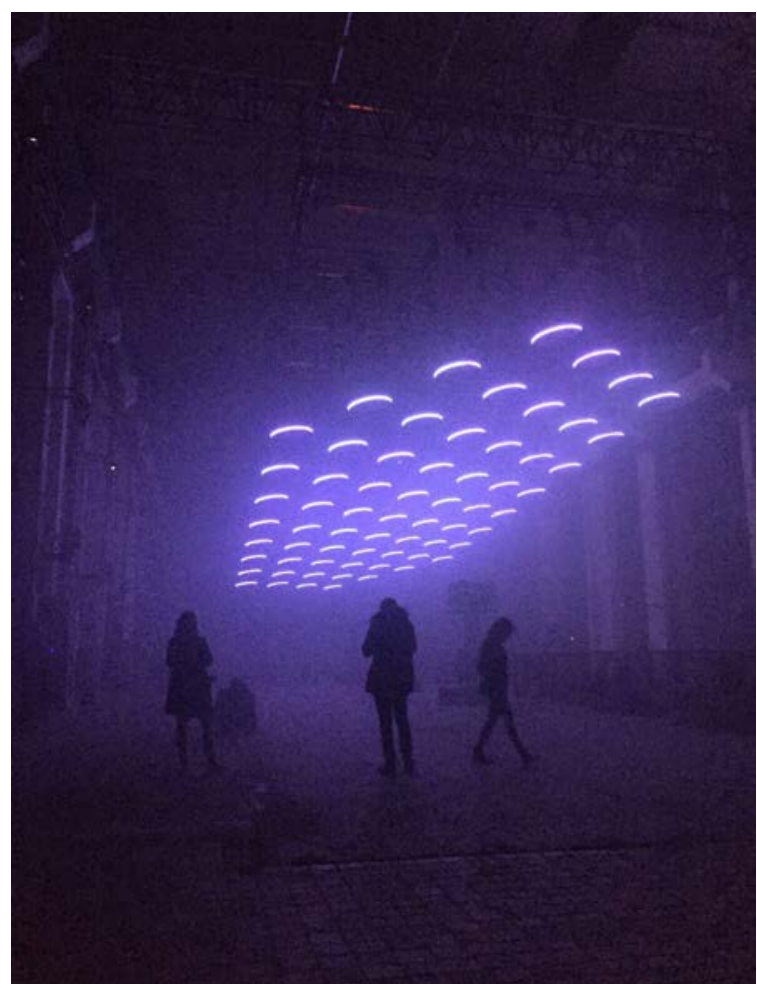

Another powerful spatial experience I recently encountered was the installation by Superflex studio, who turned the whole turbine hall into a giant adult playground. While one side of the hall was devoted to a more dynamic play with swings and shadows, the other was embracing leisure and slowing down with a beautiful carpet all along the floor plate. Both installations did not mean to impress or indulge but rather make each visitor feel the freedom and time to reflect on the surrounding, embrace the moment and create their own adaptations from this experience (Figures 9 and 10). 

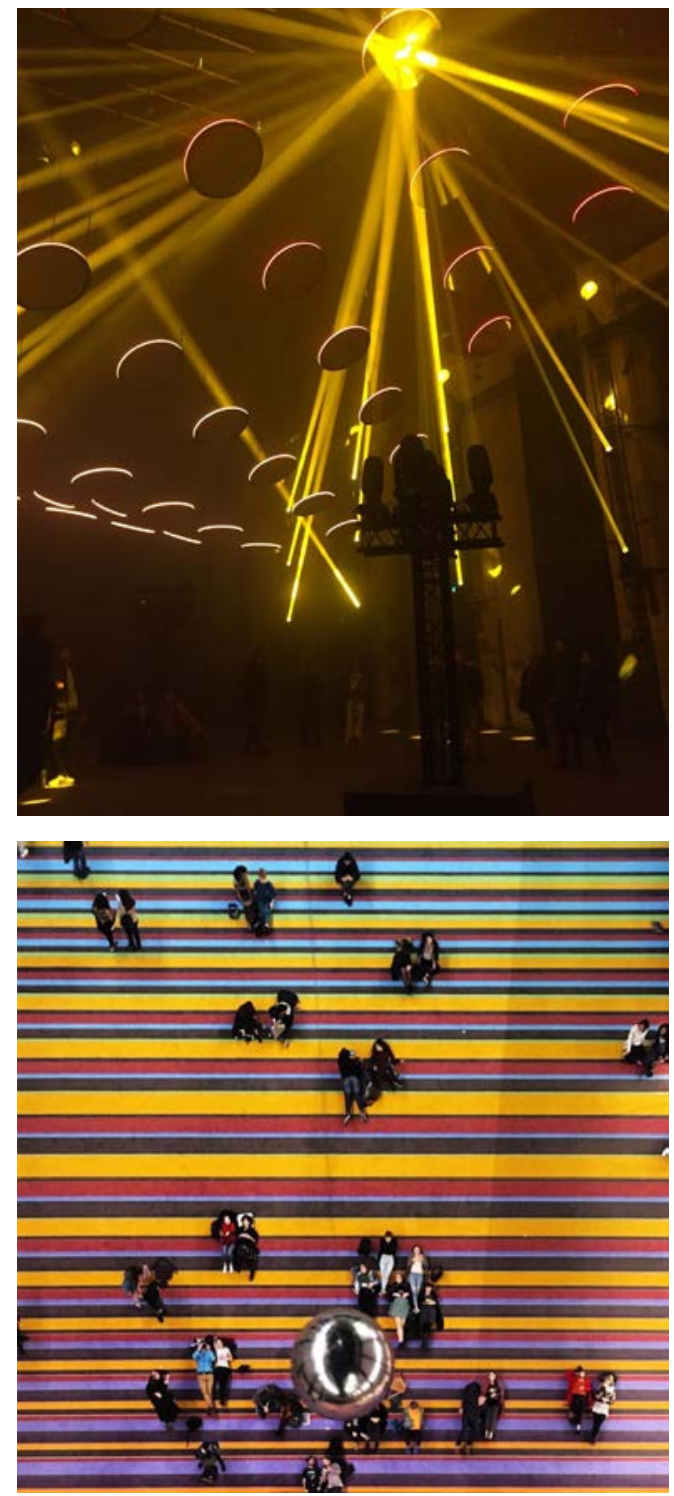

Figure 9

Tate Modern

Turbine Hall

by Superflex
Figure 10

One Two Three

Swing!

by Superflex

Empathy recognises our human entanglement with spaces and objects the way we recognise ourselves in other beings. Jorge Luis Borges beautifully describes these phenomena - a man, he says, "sets himself the task of portraying the world. Over the years he fills a given surface with images of provinces and kingdoms, mountains, bays, ships, islands, fish, rooms, instruments, heavenly bodies, horses, and people. Shortly before he dies he discovers that this patient labyrinth of lines is a drawing of his own face" (as cited in Pallasmaa, 2009 , p.124). Similarly, the notion of projective identification implies 
that the Self projects fragments of him or herself to other people he or she interacts with. Thus, one is also capable of projecting those characteristics to space. If we look more irrationally at architecture and design we can conclude that the same principles apply there as well - a communication between the body of the designer and the body of the inhabitant. Our minds become mirrors of one another through projection and identification.

Worringer (1953) intensifies that "Aesthetic enjoyment is objectified self-enjoyment. To enjoy aesthetically means to enjoy myself in a sensuous object diverse from myself, to empathise myself into it" ( $p$. 5) The principle of aesthetics, so deeply rooted in design, becomes a matter of recognizing ourselves into space or our incapacity to do so. Before it became concerned with beauty, the concept of aesthetics (from Greek aisthesthai - perceive) was related to the perception by the senses. Dostoevsky intensifies that "man can live without science, he can live without bread, but without beauty he could no longer live" (p. 189) The experience of beauty exists in the eye of the beholder and rises from grasping the complexities and mysteries of life and our reflections on it. Our sense of aesthetics is re-arranging the world with our own projection on it. We are strongly dependent upon our environmental experiences, where light, colour, tactile and audial phenomena control our physical and mental well-being. In the words of Pope Benedict XVI "If we acknowledge that beauty touches us intimately, that it wounds us, that it opens our eyes, then we rediscover the joy of seeing, of being able to grasp the profound meaning of our existence" (as cited in Pallasmaa, 2009, p. 12) Pallasmaa concludes that "the capacity to imagine, to liberate oneself from the limits of matter, place and time, must be regarded as the most human of all our qualities" (Pallasmaa, 2009, p. 17).

My interest in the concept of empathy flourished in a project about the regeneration of the brutalist estate Balfron tower in East London. I explored how softening the interior of the tower from the inside would bring neighbours closer to each other's personal lives through reflecting poetically the movement of people in space. The corridors were designed as a series of small interior gardens, visualising the presence of figures inside the apartments, while the texture of the facade was perforated with light-transmitting rods to both enhance the granulated nature of the concrete and let light through from the inside-out. By redefining functions and re-inventing the way we use materials and objects, we also re-define how we dwell in the world. If we manage to surpass the conventional, common uses of substance and matter, we are able to re-imagine our surroundings and our interiors. 


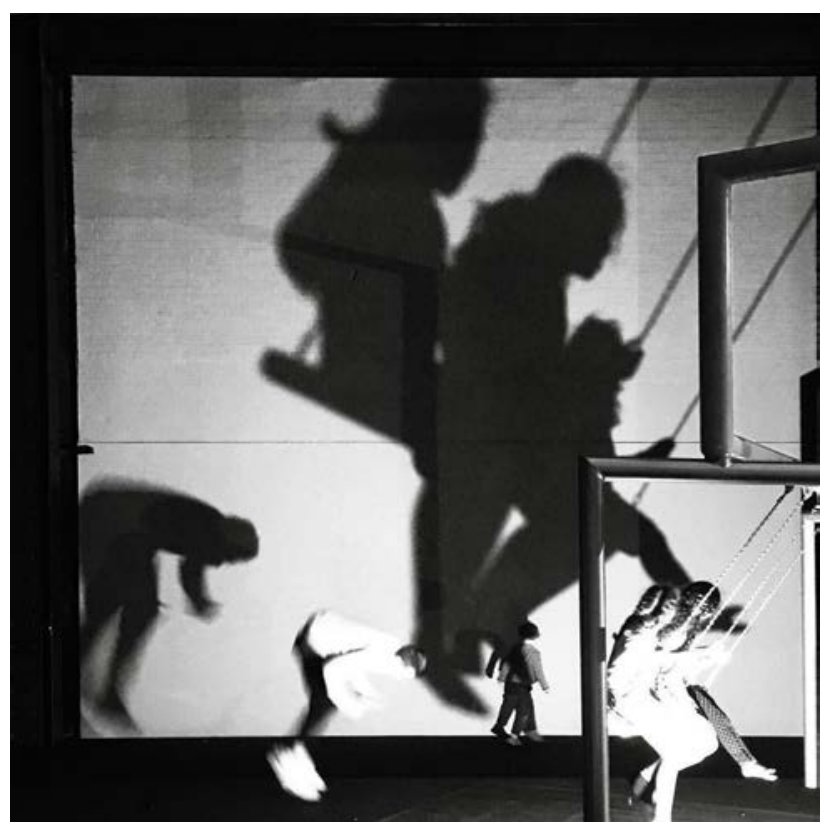

Figure 11

Vertical Village:

Author's project

Imagination occurs constantly while walking around our cities. We give meaning to things that others might discard by projecting our living characteristics onto them. We experience the world through our senses but imagination recreates it so that our world is different from that of others. Artists and designers have used the interior space as a site to try and find answers to the questions of how we dwell, by representing its physical and conceptual boundaries in spatial occupation. Re-conceptualising those boundaries also re-defines our perception of negative matter and the invisible. Pallasmaa (2009) points out that "we do not live in an objective world of matter and facts, as commonplace naive realism assumes. The characteristically human mode of existence takes place in the worlds of possibilities, moulded by our capacities of fantasy and imagination" (p. 127). In this case, positive space is replaced by the negative, physical by the imaginary and the senses are surpassed by mind. If our ability to imagine is diminished by external factors, the risk of an incomprehensible future is tremendous.

\section{The Vigour of Illusion: Transitions of Reality}

In this final section, I would like to explore the power of space to project its character on the human - through illusion. In fact, I consider this to be the most powerful tool in design as it gives a different experience beyond the visible and touchable, beyond the 
senses. Illusion is a volatile imagination, lasting from seconds to whole lifetimes, that affects the human mind with what is beyond physically there and sculpts another reality, which the person is not aware of from before. It re-creates the world as no one remembers or imagines it, taking the mind to another space, another feeling. The thin boundary between imagination and illusion could be described in terms of diverse levels of awareness and voluntary action. In the latter, the human mind could be incapable of recognising illusion from reality and experience a radically different world than the people around him, believing that his is the true one. Illusion could stimulate all senses, in fact, it very often separates the senses and creates sensuality in which what you see is not what you touch, what you smell is not what you taste. Spencer-Brown (1973) beautifully describes "Insofar as you and I see the same moon, we do so because it is an illusion that we are separate. We are the same being. We only appear separate for the convenience of filling space" (p.19).

We should remember for a brief second that the world around is a constant flow of particles in time and space. Illusion is part of our lives. All that we experience through our senses is to some extent illusion that simplifies our world from it really is. We are deluded daily within our own existence- we feel to be standing still, while we are accelerating at $67,000 \mathrm{~m} / \mathrm{h}$ around the sun, we feel solid but in fact we are mostly empty space and particles bouncing off each other. In a recent talk English producer John Lloyd explains what is invisible to us as "everything that matters, except everything, and except matter" (Lloyd, 2012). He implies that we only see the skin of things, moreover the closer we look at everything the more it disappears, becoming smaller and smaller particles until it remains empty space (Lloyd, 2012). Similarly, Lagorio (1967) implies "In the processing of images, subjectivity is most fundamental because reality is often limited to one's conscious self. If objectivity was considered the sole source of self-knowledge, life would be missing the magic of invention" (p. 21)

Illusion is undoubtedly a power that can be deluding and negative as well as positive and delightful. Illusion in architecture has the power to make people feel small and unworthy but the same has a counter effect and make human beings aware of who they are, what they are made of and why they exist. We not only have the ability to project ourselves onto other matter but also to introject its character on ourselves. This is an illusion that does not delineate from reality but creates a different reality, out of our comfort zone, stimulating all senses, not digitally but through the power of materiality, form and mostly the invisible matter between them. Space is in constant 
motion, a mixture of matter and substance that interact with each other. If we see beyond our visual perception, we may start to re-conceptualize objects not with their form and exterior but rather their invisible qualities. For example, jewellery is gold given specific character from the designer, earth can be moulded into tiles and ceramics, space is a framed void in which our interactions act on and simultaneously are influenced from. We may begin by understanding separate objects and fields as a whole. Herzog and de Meuron portray this notion in architecture implying that "matter is but a means to an end: the immaterial, mental processes of understanding, learning, and developing always have a priority" (de Meuron, 2002).

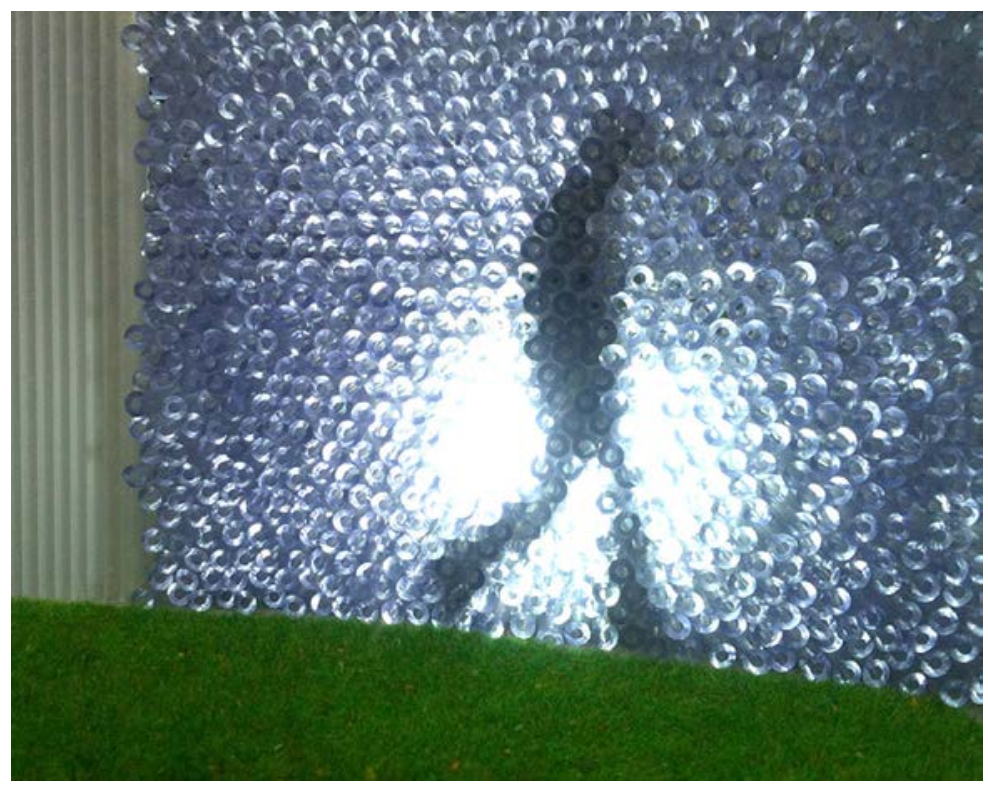

Figure 12

eArth transitions: Author's project

It is indeed architecture that renders vivid the invisible around us light we can't see but we see the illuminated surface it hits, time we can't see but we can see things around us change and carry the time inside them, we can't read each other's minds, but a space has the capacity to connect the human bodies in it as well as bridge the gap between them and its creator through empathy. Pallasmaa (2009) asserts the role of architects and designers not so much as inventors but as transformers of reality. We should aim for more illusive, dream world of irrationality, abstraction and sensual distortion, where the physical boundaries and the walls of our senses are broken.

In the installation London Fog \#03779 Fujiko Nakaya transforms the backyard of Tate modern in a space blurring the boundaries of inside and out, where one could get lost and feel like being both deep 
in the sea or high up in the mountain. Visitors were encouraged to get lost in an immersing fog of that changes continuously and disconnected them from the outside world.

Figure 13

London Fog

\#03779 by Fujiko

Nakaya

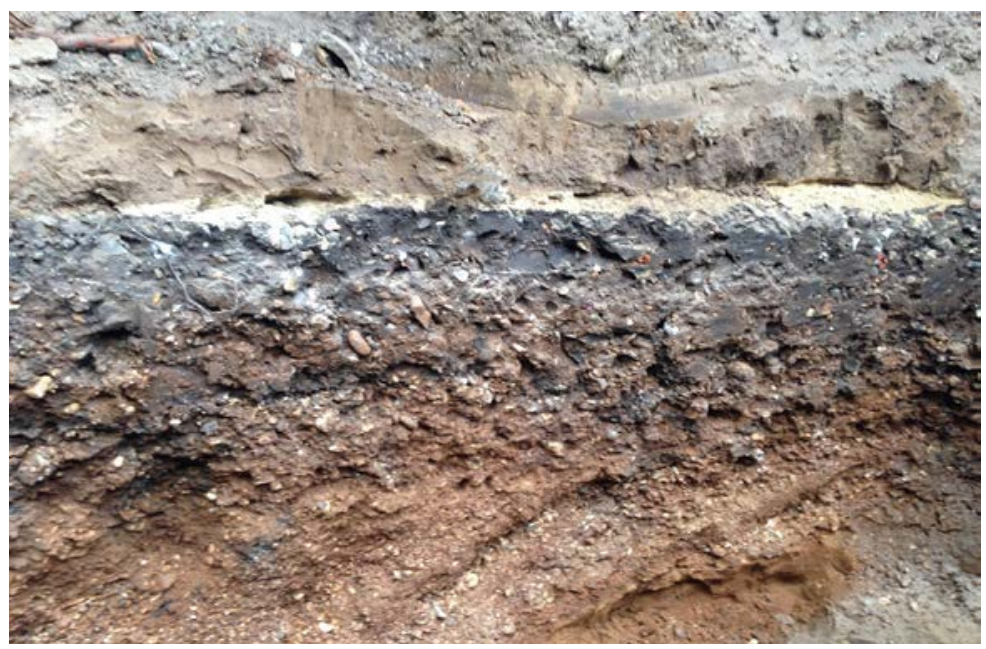

Figure 14

London Fog

\#03779 by Fujiko

Nakaya

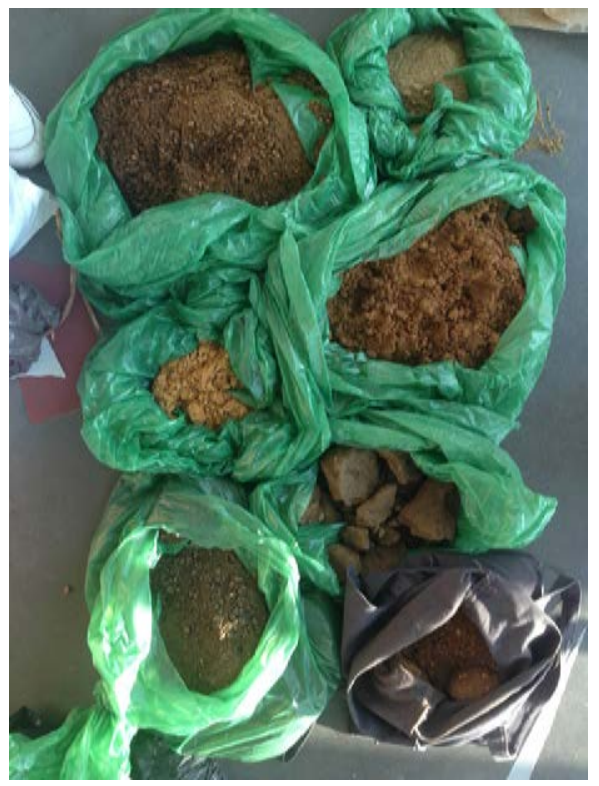

This experience has also aspired to picture the void by intensifying our awareness of it and to illustrate the physical presence of light in space by immersing the visitors in the complete void, lacking any other presence but that of the human bodies, light and air. Using a single module, BIG's 2016 Serpentine Pavilion created the illusion that one is in a different space observing from every new angle. In the White Cube gallery, artist Larry Bell also plays with spatial 
transformations and alter s our perceptions of space and matter. His brilliant piece Smoke on the Bottom completely takes the visitors into an epic illusion and disorientation from the physical. Es Devlin also created her Mirror Maze as an infinite labyrinth, which surprised with serendipity encounters and deconstructed visions.

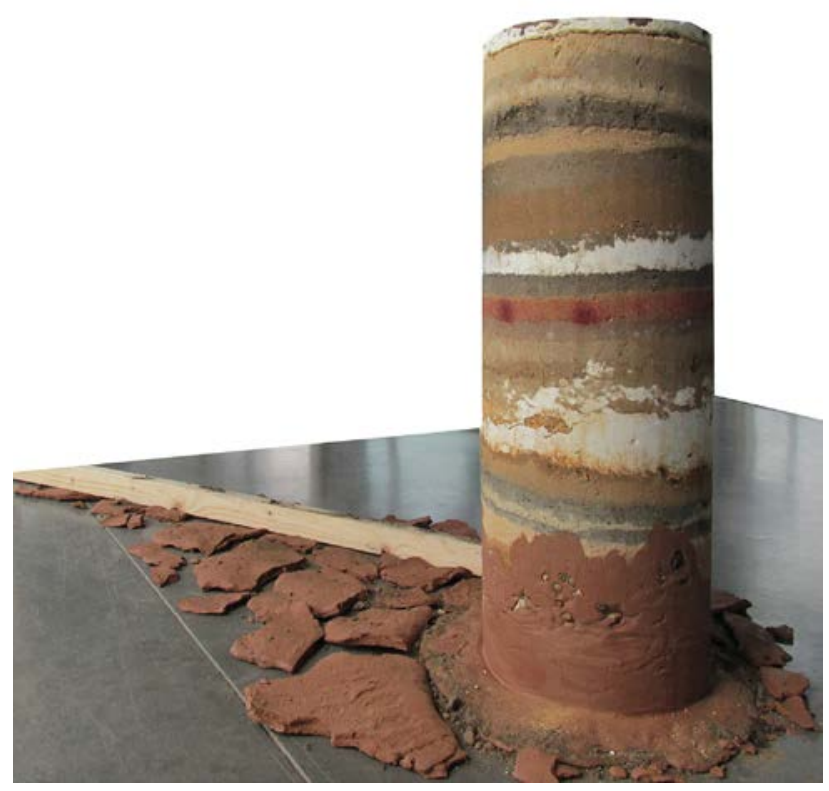

Figure 15

Serpentine

Pavilion 2016

by $\mathrm{BIG}$

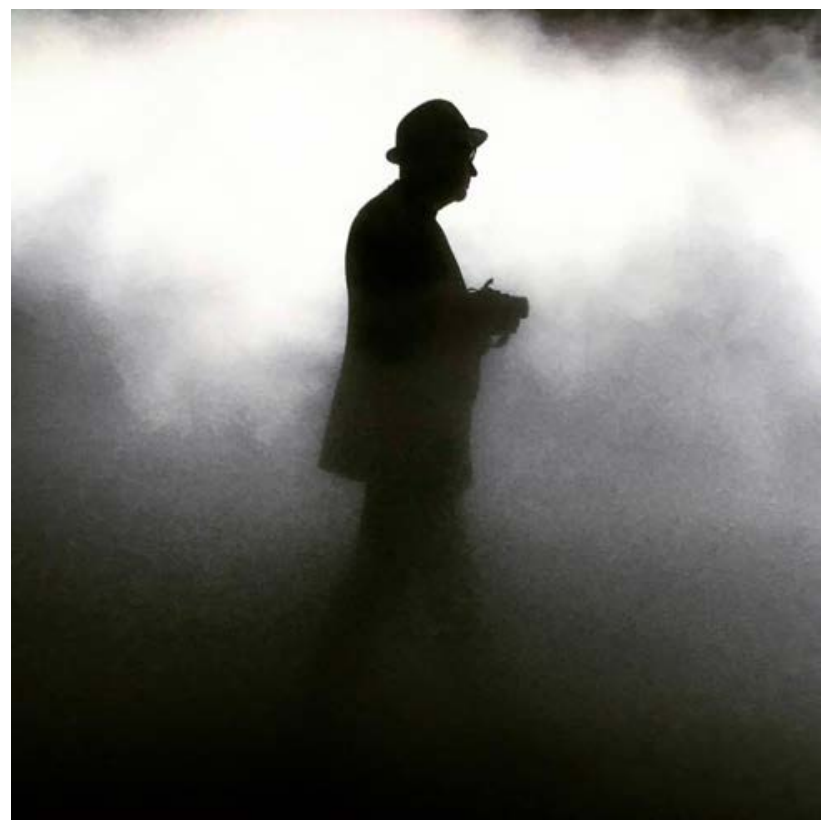

Figure 16

Smoke on the

Bottom

by Larry Bell 
Figure 17 Mirror Maze by Es Devlin

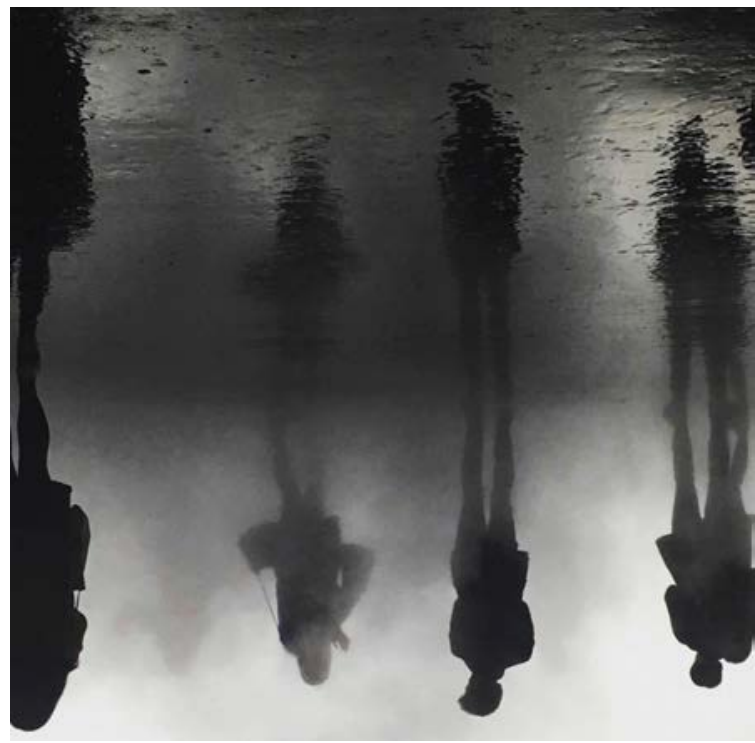

In 2014 as part of the London Festival of Architecture, I and a few other students were challenged to create a temporary installation within the Balfron Tower before it was given to developers for a complete renovation. It was a modern take on the crooked house where disorientation of the viewer was at the crux of the experience. We created a set of spatial sequences where perspective is morphed to change the relationships between audience and space, and reveal deeper stories about the building.

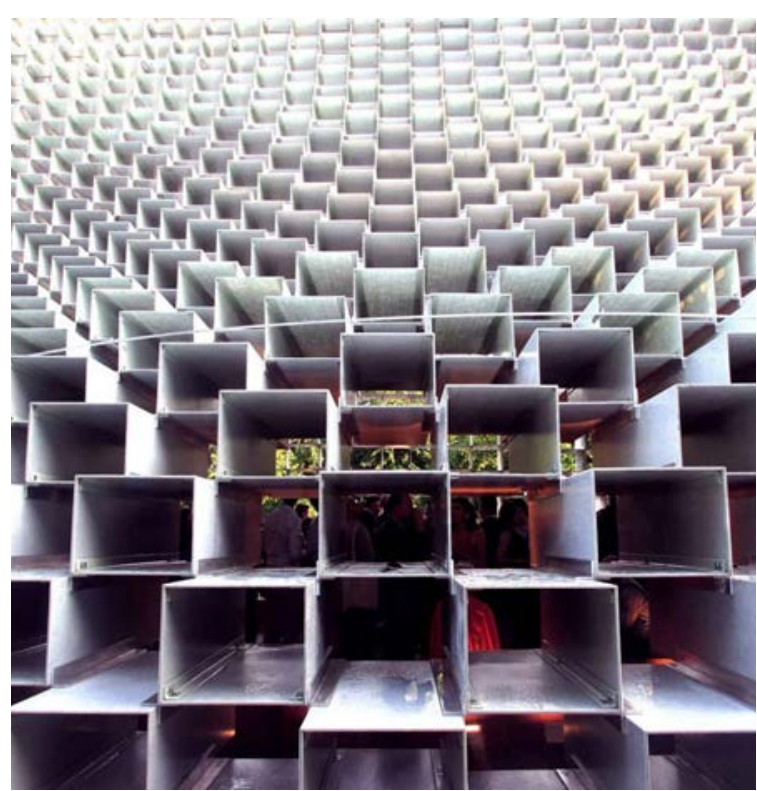


Illusion leads to creation. Our perception of architecture should surpass the notion of shelter to a space that outlines and shapes our consciousness. English psychologist and philosopher Richard Gregory (1973) claims that illusion is a natural component of life, emerging from the early age in children, who are liberated from the constrictions of society and suppressions of conventionalities and each creates their own worlds of fantasy and magic. He exclaims: "My praise of illusion is given not only because of its ability to create amusements, but also because it can sustain a power which is of inestimable value in our search for knowledge, our lasting enjoyment of life and our search for the fragile key to reality" (Gregory, 1973, p. 246).

Senses of men can be distorted and be misleading in certain situations, which intensifies our capacity to get lost and experience a diverse reality where it is not about what you see but rather how you see it. Designers should turn away from the practicalities of convention and aim to create spaces that reveal more than what is physically there, spaces that make us question, wonder and illuminate the sublime nature of our existence. Illusions are unearthly experiences that seduce us from reality as we know it. As we reinvent a space it reinvents the way we dwell in it, design it, and occupy it. The simplest act of opening a door must give delight and be a profound experience in our consciousness. It is no longer a question of object or non-object but of seeing and non-seeing, of whether we are capable of perceiving or not.

\section{Conclusion}

To open ourselves to perception, we must transcend the mundane urgency of 'things to do.'We must try to access that inner life which reveals the luminous intensity of the world. Only through solitude can we begin to penetrate the secret around us. An awareness of one's unique existence in space is essential in developing a consciousness of perception. (Holl, 2006, p. 36)

The interior is a space very often related to rationalization - a shelter, a container of solids that is assumed to bring order and control activity. As emotion outlives function, however, I believe that the physical body in architecture is only one part of its whole - its core and soul are those irrational emotions growing inside of it. This core is provisional and ephemeral, but disintegrating over time it carries the invisible link between past, present and future. Interior design contains the irrational elements essential to all art, curiosity and surprise through its spatial richness.

Interior spaces should aim to be not just intellectually stimulating 
but also provoking our innermost capacities to imagine and dream. In the three stages of the journey, I aimed to exemplify how the empathy between the interior and human is experienced physically and metaphysically. Understanding the context and identity of a place through memory, creating and visualising our dreams through imagination and finally surrendering ourselves to the spatial entity through illusion. It is not solely the designer's job to create such spaces but also the viewer to open up and see the beauty and sublime in any place we occupy. As it is not about what you see but how you see it, we need to open up our stimuli and minds to be able to truly appreciate and live our environments as well as protect them and be active participants in them.

An interior encapsulates and renders the interconnections of materials, objects and people. It is a site which challenges the way we dwell, interact, remember and discover ourselves and our world - an implicit narrative that questions our existence, our believes and worries. To resist from manipulation and exploitation, education should enable our capacities of imagination and empathy to emerge and strengthen. Real-time technologies and the fragmented images of mass media and networking take away our most human capacities of physical and mental experience in lived time. We do not need technology to visualise the fantasy, we are capable to achieve it ourselves. The desire to communicate with others is a basic human instinct, which satisfies the need to share and record emotions and experiences. It is a way in which individuals can step outside of their own worlds and step inside someone else's world, expanding our knowledge, building up new visions and perspectives. Today these are highly stimulated through technology and social media; we, however, become more and more detached, losing our capacity to share through direct confrontation.

We need to be consumers of meaning not matter and surpass the daily notion of commodities. We need substantial resources, that allow us to experience our dreams and high-most desires that make us feel alive. These would create a sense of empathy and emotional, sustainable attachment. We act on our environment and empathy is a generator of a social consciousness not just to each other but to the rest of the matter that surrounds us. Creating an emotional union and respecting the inanimate would prolong the life of objects around us.

The complex of thoughts and ideas that I have tried to engage within this paper have presented themselves amongst art and design disciplines as well as in discussions on well-being, sustainability and the mysteries of aesthetic and emotional pleasure. I have asked myself - what would it mean if we change our relationship with 
space? Would it break the vicious loop of materialism and excessive exposure in favour of defending the enigma of life?

Essential knowledge and experience are not moulded in words, concepts theories. Our communication takes place on a chemical level, and although we are rarely aware of it, most of our understanding of the world comes from the power of the invisible, not the solid. The interior is the closest connection we have to the outside world and as such, it should render vivid how our habitat touches us. The interior is fragile, ephemeral and transitional like human life. It is not the objects themselves but rather their change and movement in time. It does reflect life in any possible way the way we work, eat, entertain, make love, die. An experiment provisional as life - that reflects the fragility and beauty of nature and the living. Transcending substance is not just transparency, it is a liberation from the physical and hard, a feeling of freedom for the soul. It is in our nature to move, to be in transit, to change and be changed. Such should be the places we dwell in. Interior design as a body that reconstructs itself, builds up, hosts activities and rituals, hides mysteries, and encapsulates the void, making people attached to its soul, a jungle, a museum, an insidevisible city.

\section{References}

Calvino, I. (1974). Invisible cities. New York: Harcourt Brace Jovanovich.

Cohen, S. M. (2000). Aristotle's metaphysics. Stanford: Stanford University Press. Retrieved from http://plato.stanford.edu/ entries/aristotle-metaphysics/

Dostoyevsky, F. (2008). Demons. London: Penguin Books.

Gregory, R. L., Gombrich, E. H., \& Blakemore, C. (1973). Illusion in nature and art. New York: Scribner.

Herzog \& De Meuron. (2002). 183 Archeologie de l'imaginaire. Exhibited at Montreal, Canada.

Holl, S., Pallasmaa, J., \& Gomez, A. P. (2006). Questions of perception: Phenomenology of architecture. San Francisco, CA: William Stout.

Hollis, E. (2013). The memory palace: A book of lost interiors. London: Portobello.

Lagorio, H. J. (1967). Imagery and illusionism in architecture. Padova: La Garangola.

Lloyd, J. (2012, September 26). What's invisible? More than you think 
[Video File]. Retrieved from https://www.youtube.com/ watch?v=8EUy_82lChY\#t=80

McLuhan, M. (2005). Theoretical elaboration (Vol. II). Oxon: Routledge.

Pallasmaa, J. (2005). The eyes of the skin: Architecture and the senses. Chichester: Wiley-Academy.

Pallasmaa, J. (2009). The thinking hand: Existential and embodied wisdom in architecture. Chichester: John Wiley \& Sons.

Spencer-Brown, G. (1973). AUM Conference Transcript Session Two. Retrieved from Laws of Form: http://www.lawsofform.org/ aum/session2.html

Worringer, W. (1953). Abstraction and empathy: A contribution to the psychology of style. New York: International Universities. 